\title{
Postgraduate Education in Mining Engineering under the Parent Industry Status
}

\author{
Yaobin Shi \\ College of Resource and Environmental Engineering \\ Wuhan University of Science and Technology \\ Wuhan, P.R.China
}

\author{
Yicheng Ye \\ College of Resource and Environmental Engineering \\ Wuhan University of Science and Technology \\ Wuhan, P.R.China
}

\begin{abstract}
In order to provide effective judgment and suggestions of postgraduates' development in the future, personnel training status and characteristics of mining engineering postgraduate were analyzed, combined with the new situation of mining engineering's parent industry. The results show that, with the rapid development of the mining engineering parent industry, comprehensive utilization of resources continues to promote, industry integration continues to accelerate, innovation in the industrial market continued to increase, technological and economic transformation continued to accelerate. It directly affects the demand and structure of high-quality talents in parent industry, especially in mining and manufacturing, and changes the characteristics of college talent education. It should be pay more attention to subject characteristics and industry-university-research synergic development. And the quality assurance system for talents cultivation should be improved, multidimensional and synergy cultivating system should be built based on different requirements.
\end{abstract}

Keywords-postgraduate; mining engineering; parent industry

\section{INTRODUCTION}

With the expansion of postgraduate enrollment scale in China, the number of postgraduate is increasing. In 2017, there were 805 thousand students enrolled, 2.64 million in school and 578 thousand in graduates in postgraduate education [1]. Mining engineering, as one of the earlier majors with the development of industry, postgraduate education has developed rapidly in recent years. The enrollment scale of mining engineering sustained increase, of which national enrollment of 2400-2600 per year, the total number of graduates nearly 16 thousand in only 2012-2017.

The number of mining engineering postgraduate has grown rapidly. The corresponding parent industry has suffered from the downward pressure of the economy, the restructuring of industry and the innovation of iron ore resource allocation. This phenomenon changes the supply and demand relationship of sophisticated talents between supply side structural reform and industrial structure optimization. The consequence, which further highlights the flexible and innovative contradiction of talent cultivation, demand and development, has affected the education and cultivation of mining engineering postgraduate [2]. For one thing, the enrollment scale of postgraduate will continue to expand steadily considering the following factors, such as the great demand of high-tech talents for innovation-driven development, the self-development of higher education, and the demand of postgraduates for graduate education. Simultaneously, the overall education and training model will develop more openly and autonomously, and the mutual competition between academic and scientific research innovation will also become more intensely, which will bring new threats and challenges to the cultivation of postgraduate in mining engineering. For another, with the rapid development of the utilization of iron ore resources in recent years, the parent industry, which is mainly mining and steel manufacturing, is closely related to the education and training of postgraduate in mining engineering. This industry exist prominent phased structural problems in comprehensive production capacity and talent allocation. Under the influence of the parent industry for many years, the corresponding universities have a periodic development model for postgraduates' training environment, training methods and training effectiveness to some extent $[3,4]$. The result has caused the strategic pressure of postgraduate education and training to be highlighted, which not only changed the structural training model, but also put forward stricter requirements of the training and education for postgraduate in mining engineering.

\section{EASE OF USING THE DEVELOPMENT OVERVIEW OF THE PARENT INDUSTRY FOR MINING ENGINEERING DISCIPLINE}

In recent years, from the perspective of the major industry sectors of graduate employment for mining engineering discipline, there are two industries with better employment prospects. One is based on the mining of metal and non-metallic mineral, and the other is based on the manufacturing of steel and metallurgy. Therefore, the research, starting with the development situation of iron ore resources, intends to analyze the development status of the parent industry for mining engineering discipline. 


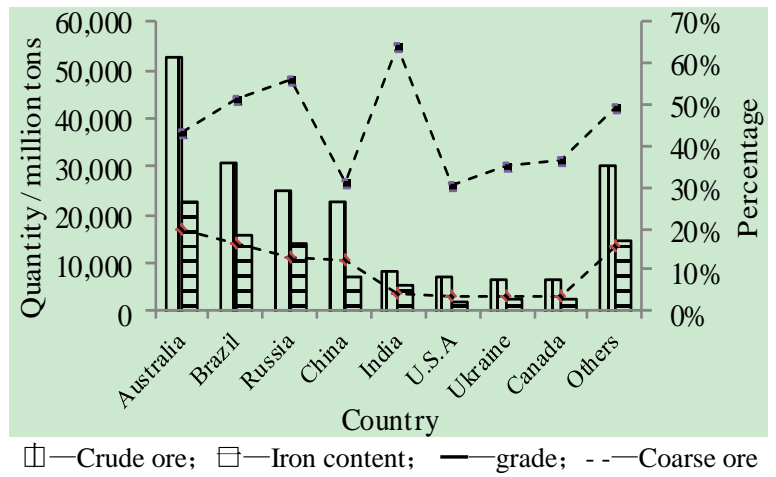

Fig. 1. Distribution of global iron ore resources in 2014.

According to the statistics of 'Pyrite Ore Industry InDepth Research and Investment Prospects Report in 20152020, China', by the end of 2014, the world's reserves of iron ore were approximately 190 billion tons. These iron ore resources are mainly distributed in Australia, Brazil, Russia and China. As the "Fig. 1" shows, the total reserves of the four countries accounted for $61.59 \%$ of the world's reserves.

Although China's reserves of crude iron ore, abundant and plentiful, accounted for $12.11 \%$ of the world's total reserves, the average resources grade of iron ore were only $31.30 \%$, far below the world's average resources grade of $47.79 \%$. From this phenomenon, it can be seen that the resources have lower iron content and a lower grade. In addition to this, domestic iron ore resources are relatively poor.
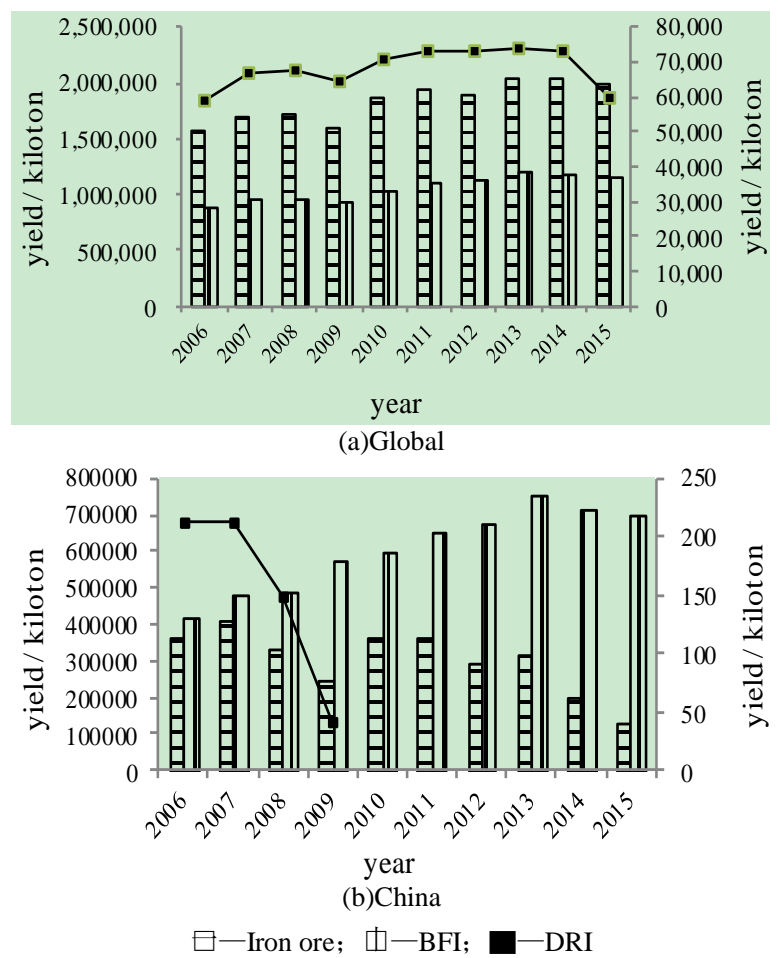

Fig. 2. Production status of iron ore resources and iron and steel industry.

With the changes and innovations of the comprehensive utilization for iron ore resources over recent decades, the parent industry of iron ore resources, especially the iron and steel smelting industry, is affected enormously. "Fig. 2" shows that, according to World Steel Association, annual output of global iron ore continues to increase overall. In 2015, global iron ore production increased by $30.18 \%$ compared with 2006, whereas the annual output of iron ore in China continues to decrease as a whole. In 2015,domestic iron ore production decreased by $45.27 \%$ compared with 2006.As the iron and steel industry in the downstream of iron ore resources, the annual global output of blast furnace iron (BFI) and reduced iron (DRI) are similar to that of iron ore. The annual output of domestic blast furnace iron shows an overall growth trend, and the production of reduced iron continues to decrease.

The continuous decline in domestic iron ore production and increase in blast furnace iron production have directly increased the dependence of domestic related industries on imported iron ore, which has affected the transformation of the mining capital market. On the one hand, in recent years, international mining capital flows have shown changes in short-term speculative capital, accelerated capital flows, shortened capital flow cycles, and increased demands for the expansion of capital of multinational mining companies, which directly reflects the transformation of the operating mode of various types of mining capital including iron ore resources. Single, inherent and traditional local collaboration converts to multiple, multilevel and multidimensional regional collaborative cooperation; On the other hand, as is shown in "Fig. 3", this situation, the continuous decline in domestic iron ore production and continued growth in iron making production, have directly contributed to the continued increase in the import amount of iron ore and the investment of fixed assets in the domestic mining industry. This has accelerated the integration of iron ore resources related industries, market innovation and economic transformation.

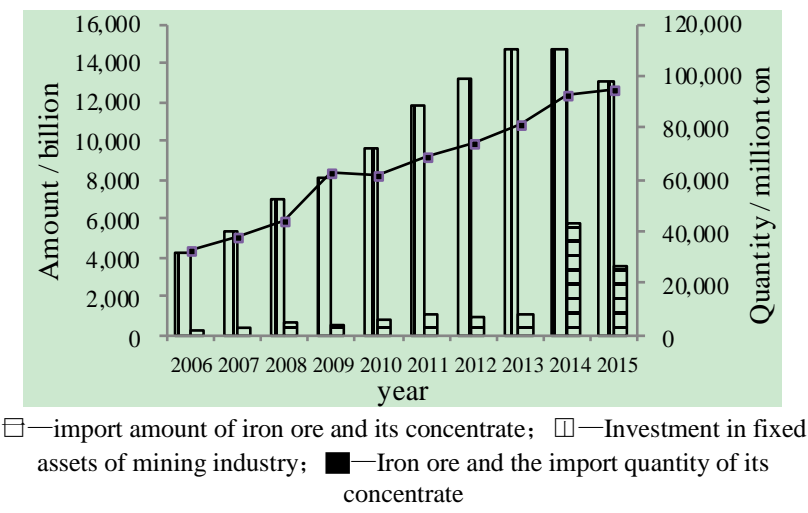

Fig. 3. Import of iron ore resources in China.

With the rapid demand of changes in iron ore resource utilization and related industries, the depletion of iron ore resources has accelerated, and the pressure on destocking of steel has increased. Under this circumstance, the phrased and structural contradictions in the utilization of integrated production capacity in the industry have been highlighted. Correspondingly, in the continuous optimization of the industry's talent pool, structural adjustment and economic restructuring, the demand for high-quality talents, in the 
mining and manufacturing industries related to iron ore resources, has affected the structure of supply and demand in the industry to a certain extent. This result has directly changed the talent cultivation characteristics of professional education in colleges related to the industry.

\section{The Cultivation OF PostgRaduAte IN Mining ENGINEERING}

Mining engineering, related to the utilization of iron ore resources, is one of the professions that appeared earlier with industrial development. It has grown rapidly in recent years. The scale of training has expanded continually, and the number of graduates has increased year by year. From 2012 to 2016, the national graduate university of mining engineering enrolled 1,700-2,400 per year, with the total number of graduates reached as high as 15 thousand. The scale of postgraduate training in mining engineering is growing rapidly, and the relevant industry transformation and innovation are deepening continuously. As a whole, the contradiction among objective supply, demand and competition in the cultivation and education of postgraduate in mining engineering is still outstanding.

\section{A. Enrollment Situation}

On the macro level, the enrollment scale of postgraduate will continue to expand steadily with the great demand of high-tech talents for innovation-driven development, the self-development of higher education, and the demand of postgraduates for graduate education. The enrollment and cultivation scale of postgraduate in mining engineering will continue to increase. Taking China University of Mining as an example, it has enrolled postgraduate of mining engineering (only full-time postgraduates) in the past five years. The enrollment scale as a whole has shown an increasing trend with an increase of more than $17.39 \%$.

\section{B. Culture Conditions and Quality Situation}

Overall, with the evolution of universities, postgraduate cultivation units and scientific research institutes, the cultivation condition and quality form a collaborative innovation model of production, learning and research based on "research projects, industrial demand orientation, technology research and developments as a means, and innovation practice". Postgraduates, from universities and engineering research institutes, are significant researchers in the national and industry leading or first-class scientific research institutions, technological innovation bases, and coconstruction of scientific research cooperation platforms. They undertake or participate in abundant national key projects and university-enterprise cooperation projects, in which the content and quality of training are enriched. However, while the iron ore resources have been continuously utilized and the relevant parent industries have been transformed, the corresponding engineering projects and university-enterprise cooperation projects have also been influenced to some extent. At the same time, the changes in the external environment, talent demand, cultivation modes, and training requirements have a great impact on postgraduate in mining engineering.
In practice, the conditions, requirements and modes of cultivation for postgraduate in mining engineering are constantly optimized and promoted. The industry characteristics will be more pronounced. While the quality of postgraduate education is effectively guaranteed, the situation it faces will be even more severe.

Judging from the quality of postgraduate education and training, the academic research and innovation ability has been continuously improved. As Liu Yan dong pointed out at the National Quality Work Conference of Graduate Education in 2015, postgraduate students contributed $36.8 \%$ to international high level papers and $32.3 \%$ to domestic high quality research achievement from 2011 to 2012. Take the patent for instance. According to statistics of the State Intellectual Property Office, the "Fig. 4" shows that the average percentage of domestic and foreign patent applications granted by Chinese universities has reached $20.26 \%$ in recent years. The majority of postgraduate applying or participating account for most of them. For the mining engineering discipline, although facing the dual pressures of downturns and transitions in the industry, the overall quality of postgraduate has continued to increase for the past few years. In the case of Wuhan University of Science and Technology in 'Fig. 5", the amount of scientific research achievement of postgraduate in mining engineering (only academic papers and national patents as statistics) has increased annually over the past five years. Annual average increase in the volume of academic papers and patents is $23.01 \%$ and $42.25 \%$ respectively.

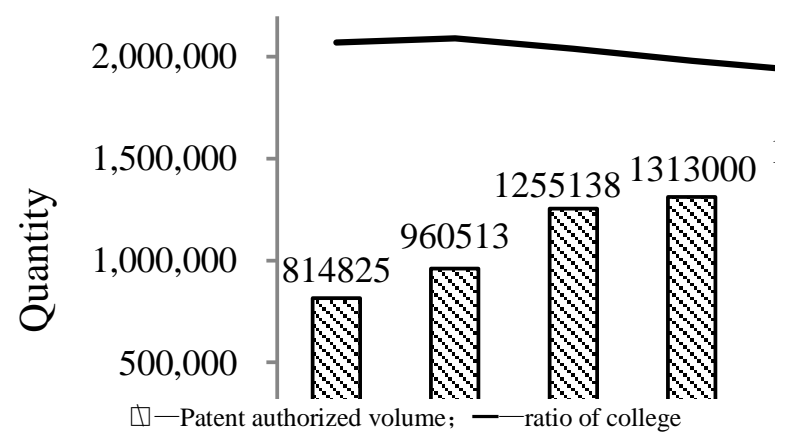

Fig. 4. Application of patent authorization at home and abroad in 20102015 .

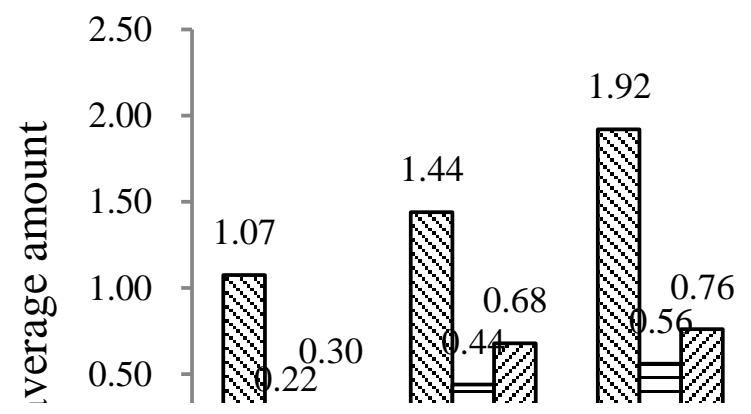

$\square$-Academic articles; $\square----$ Patent for invention; $\square$-Utility model patent Fig. 5. Average of achievements of mining engineering postgraduate in WUST. 


\section{Employment Status}

Overall, the employment conflict of postgraduate in mining engineering is more conspicuous than the structural conflict. That is to say, there are practical and cyclical lags between social supply and demand. The main reason is that the academic innovation and entrepreneurship abilities of postgraduate in mining engineering need to satisfy two training requirements. One is degree awarding, and the other is highly qualified professional with innovation spirit and engaged in scientific research, teaching, management, or independent technical work. But in reality, the demands and salaries of the parent industry grow slowly, even negatively, in the cycle of talent reserve, industry transformation, and top-lever design over the past several years.

According to data from the National Bureau of Statistics in "Fig. 6", the employment of state-owned units in the mining industry continued to decline from 2011 to 2015, with the largest decline reaching $62.06 \%$ in 2013. Correspondingly, employment of other units in the mining industry continued to increase from 2011 to 2013, and then ushered in negative growth with an average decrease of $4.18 \%$ from 2013 to 2015 . Moreover, compared with 2011 , the average wage and increase rate of the employed people in the mining industry is much lower than that of the national urban units in 2015.

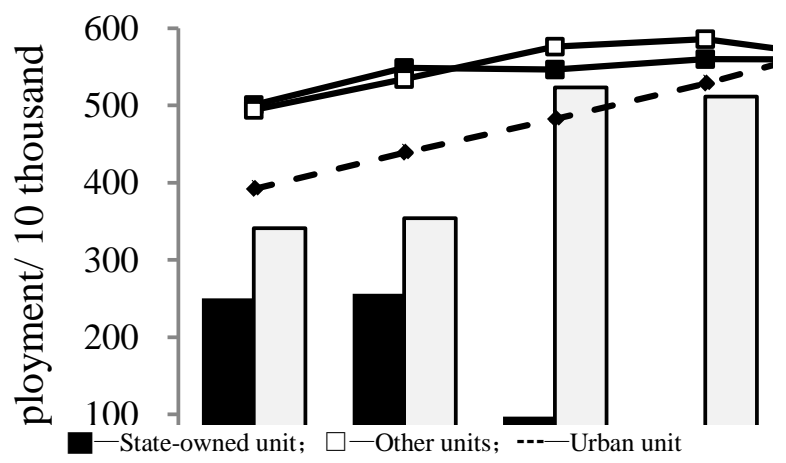

Fig. 6. Employment status of mining industry in 2011-2015.

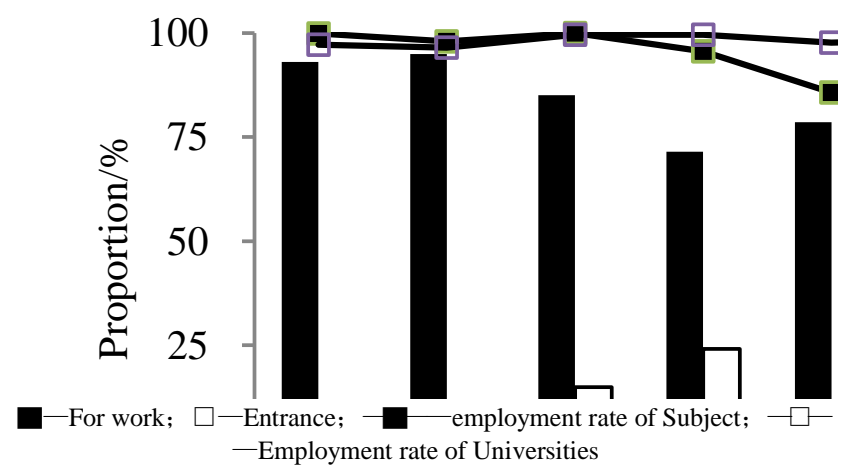

Fig. 7. Employment of mining engineering in some universities of 2015.

From the employment situation of 2015 graduate students of mining engineering (including mineral processing engineering) in six colleges, such as China University of Mining and Technology, it can be seen that this situation was generally optimistic, with an average employment rate of
$95.8 \%$. The rate was slightly higher than the national average of $94.8 \%$ for postgraduates, which was released by 2016 Graduate Employment Quality Study. The proportion of students entering the university and their intentions for further study was relatively large. Among them, the proportion of postgraduate in mining engineering at Beijing University of Science and Technology and Northeastern University were as high as $14.9 \%$ and $24.2 \%$ respectively.

\section{CONCLUSION}

In order to provide strategic talent support for economic growth and industrial upgrading during the 13th Five-Year Plan, as a basic discipline of mining engineering, the cultivation of postgraduate needs to pay more attention to the innovation of the mechanisms and models of the professional subject quality.

To begin with, take the requirements of postgraduate education and training as the starting point. Pay attention to the industry characteristics and the parent industry development of production, education and research [5]. Faced with the major demands of industry and fierce competition in universities, these topics, such as meeting industry development strategies, optimizing the distribution of disciplines, and building research universities with distinctive characteristics, are still the mainstream discourse to promote university features. On the basis of maintaining the traditional disciplines of mining engineering education, university educators should expand the characteristics of disciplines, strengthen common research areas with moderate interdependence, deepen the characteristic research areas with high dependence, and promote the structural construction of basic disciplines. At the same time, in view of the common, advanced, and key technical issues in the industry, collaborative company, a practical strategic base, conducts joint study by sharing research teams, platforms, and experimental equipment. This measure will contribute to the gradual, progressive, and effective development of postgraduate subjective ability. In this way, the development of discipline specialties and the level of scientific research and innovation will be further promoted.

Secondly, focusing on the requirements of each stage of postgraduate training, it will be necessary to combine the development needs and actual requirements of the parent industry so as to innovate the multidimensional education and distribution mechanism. In other words, at different stages, levels and fields of postgraduate training, the promotion of academic, scientific research, innovation and entrepreneurial ability will improve postgraduate in a hierarchical, stepwise, and progressive manner.

Furthermore, based on the basic construction and platform expansion, systematically analyze time stratification, apace layout, and demand levels including all aspects, factors, and processes. Deepen the development needs of the parent industry, and build a mechanism to meet the requirements of the times. This requires the construction of postgraduate teams, platforms and projects from the basics, structural, and connotative aspects. In the end, an approach, hierarchical, phased and progressive, will be adopted to enrich the 
platform construction, institutional guarantees, and practical effectiveness of postgraduate education.

\section{ACKNOWLEDGEMENT}

This research was financially supported by "Excellent Project on University Student affairs, Hubei, P.R.China (2017XGJPB3017)", and "Project on Humanities and Social Sciences of Educational Committee, Hubei, P.R.China (18Q025)".

\section{REFERENCES}

[1] National Bureau of Statistics of the People's Republic of China. People's Republic of China 2017 national economic and social development statistical bulletin[N]. People's daily, 2018-0301(10).

[2] J.L. SHENG,Y.C. YE, X.Y. LIU, et al. Research into the reform of talent cultivation mode of mining engineering major under the new situation. J. China Mining Magazine, vol. 25, pp. 157-160, July 2016.

[3] Worldsteel Committee on Economic Studies . Steel Statistical Yearbook 2015. Brussels, World Steel Association, 2015.

[4] B.Y. HUANG. Further Graduate Education Reform for Higher Quality. J. Academic Degrees and Graduate Education, No. 12, pp. 16. Dec. 2015.

[5] X.H. QIAN, J. CHEN. Research On The Dependency Relationship Between The Universities With Industrial Features And The Parent Industry. J. research in higher education of engineering, No.1, pp 7175. Jan. 2014 